\title{
SELECTION OF OPTIMAL INVESTMENT VARIANT BASED ON MONTE CARLO SIMULATIONS
}

\author{
Janekova, J.; Fabianova, J.** \& Kadarova, J. ${ }^{*}$ \\ * Institute of Management, Industrial and Digital Engineering, Faculty of Mechanical Engineering, \\ Technical University of Kosice, Park Komenskeho 9, 04200 Kosice, Slovakia \\ ${ }^{* *}$ Institute of Logistics and Transportation, Faculty of Mining, Ecology, Process Control and \\ Geotechnology, Technical University of Kosice, Park Komenskeho 14, 04200 Kosice, Slovakia \\ E-Mail: jaroslava.janekova@tuke.sk, jana.fabianova@tuke.sk, jaroslava.kadarova@tuke.sk
}

\begin{abstract}
This paper presents a methodology for the selection of an optimal investment variant using Monte Carlo simulation and OptQuest optimization. The decision-making process also includes risk analysis. Investment variants involve renewal and development of production equipment. Two approaches to investment decision making are introduced. The first approach is based on the analysis of the distribution function of Net Present Value (NPV), and the rule of mean value and coefficient of variation is used as the decision criterion for determining the profitability of investment variants. The second approach, based on the cumulative probability distribution of $N P V$, provides a comparative assessment of the investment variants using stochastic dominance rules. Both approaches lead to the choice of the same investment variant. In order to increase the profitability of the selected investment variant and reduce its risk, OptQuest optimization is subsequently implemented. The introduced approaches can be a useful support tool in investment decision-making.

(Received in January 2021, accepted in April 2021. This paper was with the authors 1 month for 2 revisions.)
\end{abstract}

Key Words: Investment, Decision-Making, Monte Carlo Simulation, Risk Assessment

\section{INTRODUCTION}

Corporate investments are necessary for the survival and growth of the company and mostly concern the modernization and development of the technologies. Investments that lead to better use of resources, energy-saving, and waste reduction are significant factors of sustainable development [1]. However, investing is associated with risk. Companies have to face social, macroeconomic and market risks that affect investment expenditures and returns. Therefore, investment decision-making is often a complex multi-criteria problem.

Risk assessment is a considerable part of investment decision-making. Various methods are applied in investment risk assessment. From relatively simple methods not requiring expert knowledge or extraordinary technical equipment, to highly sophisticated methods. The scientific literature database contains many resources in this area, mostly of the type of realword studies. From the literary review, it is evident that the widely used method of risk assessment is the fuzzy method. Authors of $[2,3]$ applied fuzzy logic methods in evaluating and analysing investment risks. The probabilistic hesitant fuzzy set [4] and intuitionistic fuzzy linguistic AHP method [5] were used for handling uncertainty in investment decision making. Investment risk factors of renewable energies were weighted by the fuzzy-analytic network process in [6]. Another group of methods widespread in risk assessment are methods based on neural network approaches. For example, the deep neural network was used in [7] to evaluate the overseas investment risks of enterprises. Likewise, Zhang [8] used the fuzzy neural network model of artificial intelligence method to assess credit risk of enterprises.

As outlined above, the investment variants evaluation is a multidimensional problem. One of the proper ways of choosing the best investment variant is the modelling approach and simulation. Distribution functions, statistical characteristics, or stochastic dominance were used in project evaluation and investment decision-making. For example, in the paper by [9], 
simulation, stochastic dominance rules and multiple criteria decision aiding procedures were employed for solving an investment projects selection problem. Also, in [10], the authors applied stochastic dominance of the first and second orders and compared the most effective investment decisions. Similarly, Repiský [11], by comparing distribution functions of five variants of projects, identified the optimal investment strategy. Because of the risk analysis, Kauffman et al. [12] performed project value sensitivity analysis and the use of simulationbased least-squares Monte Carlo valuation. On the other hand, the case of optimizing investment decision dilemma using a discrete event simulation model was presented by Vrecko et al. in [13]. Another application of simulation models we can find in professional works [14-16].

Monte Carlo simulation and risk analysis is often used in connection with investment into large corporate or government projects. In the paper [17], the authors investigated financial risk associated with highway infrastructure PPP projects applying a standard risk-analysis model (NPV-at-risk tool supported by Monte Carlo Simulation). Likewise, Albana [18] used the same software tool in the case of a power plant to explore profitability of an investment project. Effects of risks on the investment costs of international rail projects using Monte Carlo simulation were explored by [19]. Monte Carlo simulation for quantitative risk assessment was used by [20,21]. Risk assessment is crucial for investment in electricity markets. Pringles et al. [22] presented a methodology for assessing the economic value of a photovoltaic power plant under uncertainties. The authors used the Least Square Monte Carlo simulation method. In the field of architectural engineering, authors of [23] employed the Monte Carlo method in the selection of the best option between different possibilities. In [24], the authors investigated the relationship between banks' capital ratios and riskiness through extensive Monte Carlo experiments. In the paper [25], the Monte Carlo simulation method was used to identify the relative contribution of sustainability criteria to property value risk. Monte Carlo simulation is used in decision-making in combination with other methods as well. For instance, Samokhvalov [26] combined fuzzy estimates and the Monte Carlo simulation in risk assessment of innovative projects. Kannan et al. [27] applied Monte Carlo simulation to analyse sensitivity of a multicriteria decision method. An extensive literature review about combining heuristics with Monte Carlo simulation was presented by Juan et al. [28]. Their review describes a general methodology that allows for extending metaheuristics through simulation to solve optimization problems.

The aim of the paper is to present a methodology for the selection of an optimal investment variant using Monte Carlo simulation and OptQuest optimizations. We assess seven investment variants that differ in the extent of the renewal and development of current production. The variants are evaluated from the view of economic efficiency and risk. The evaluation is based on the NPV method and analysis of probability distributions of NPV.

\section{MATERIALS AND METHODS}

\subsection{Case study description}

The case study deals with the assessment of the economic efficiency of an investment project. The investment is focused on the renovation of existing or the acquisition of new production equipment in a company dealing with potato processing. The current production is inefficient due to the wear and tear of production machines and equipment (period of use approx. 15 years) and subsequent impacts on the growth of energy costs, material consumption, repair and maintenance of machines and equipment. The current treatment method generates a high proportion of waste that is not used. However, for the most part it is a quality material which is not suitable for further processing due to dimensional reasons. In addition to the mentioned reasons, the need to invest is also caused by insufficient production capacity. 
The above facts initiated the intention to invest in the renewal of production facilities or development. The current state of production takes place in the sequence BP-main production (sorting, peeling), which in separate branches are followed by SP1 - secondary production 1 (cutting potatoes into various shapes) and SP2 - secondary production 2 (production of chips). Renewable investments concern the modernization of existing production facilities and development investments concern the acquisition of a production line to produce a new product from currently unprocessed waste (NP - new production).

\subsection{The methods and procedure}

Investment decision-making is carried out by a simulation approach applying the Monte Carlo method and optimization. The economic efficiency of the investment variants is evaluated through dynamic financial criterion Net Present Value $(N P V)$. The procedure for solving the problem is shown in Fig. 1.

Step 1: Determination of investment variants $(1-7)$ of the project

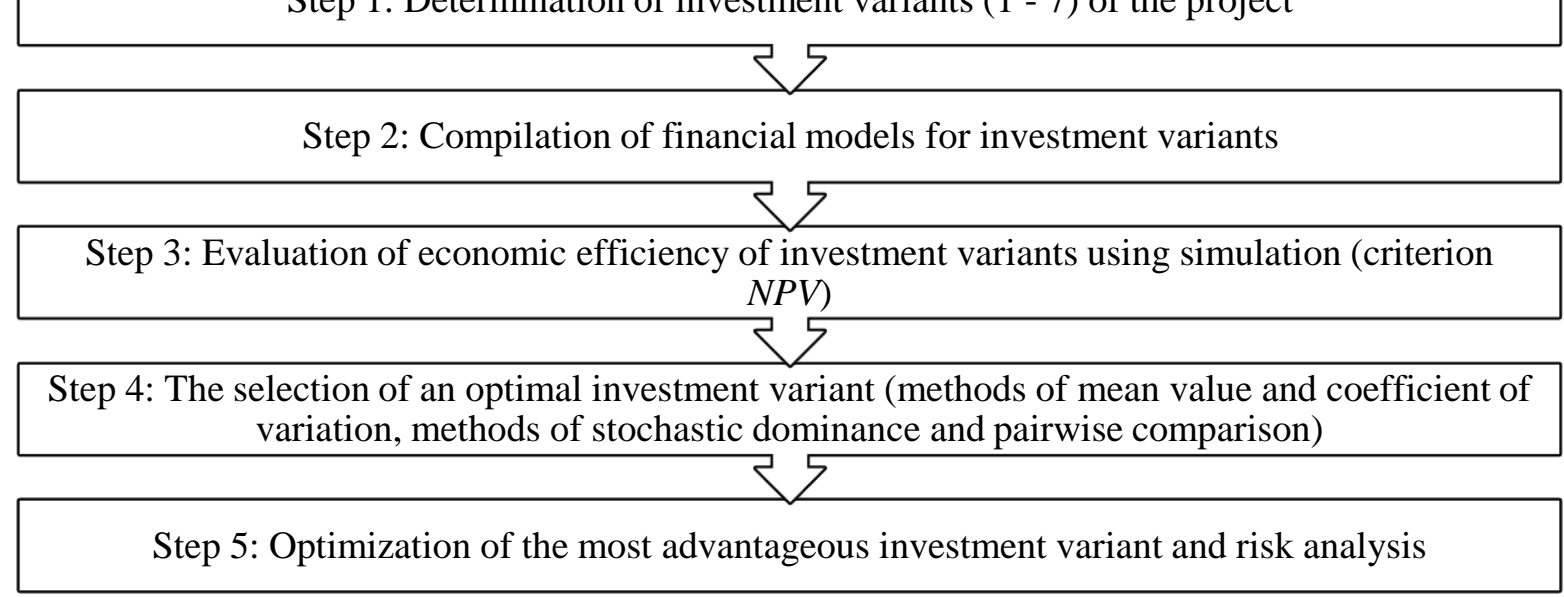

Figure 1: Problem solving procedure.

\section{Determination of investment variants ( 1 - 7) of the project}

The proposed solution is processed alternatively. The individual investment variants are considering the renewal of existing production equipment and the acquisition of new production equipment to expand production with a new product by processing unprocessed waste. The diagram in Figure 2 shows the individual investment variants, while production that will not be modernized (no investment spending) is marked with a symbol with the index "c" (current status). Production with investment is highlighted in bold.

\section{Compilation of financial models for investment variants}

The mathematical model of individual investment variants is based on the incremental method. It means that the only those revenues and costs are considered in the calculation which the given investment variant will bring in addition to the current situation.

The company currently generates up to $30 \%$ waste from the total input material processed. The investment in the main production is expected to increase the production capacity by one third. As no significant increase in sales of main production is considered due to its low profitability, the company is forced to increase capacity only for SP1 or SP2, or both. The percentage shares of individual productions on the increase in production volume for individual variants are presented in Table I. 


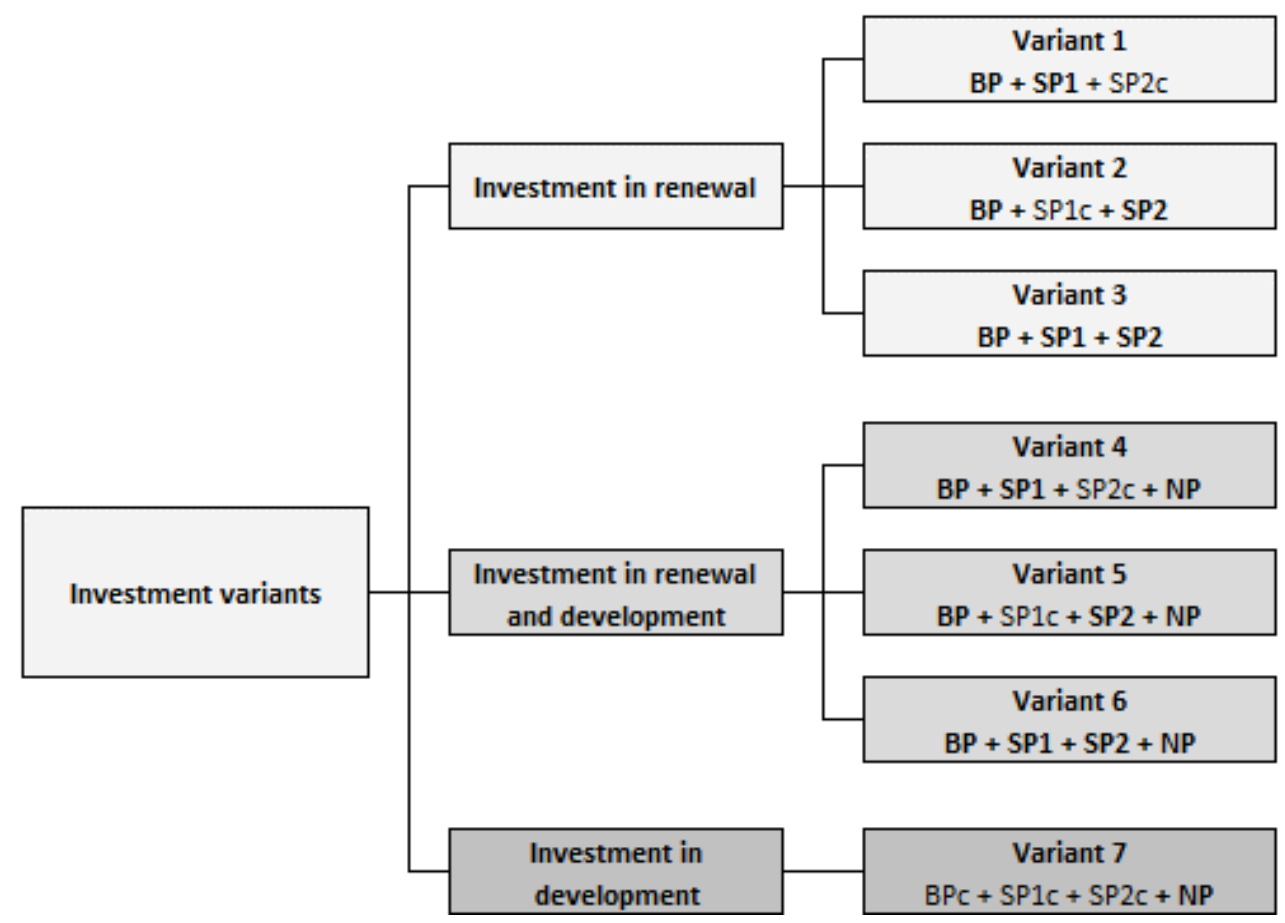

Figure 2: Investment variants of the project.

Table I: Planned annual production volumes by investment variants and type of production.

\begin{tabular}{|c|c|c|c|c|c|c|}
\hline \multirow{2}{*}{$\begin{array}{c}\text { Investment } \\
\text { variant }\end{array}$} & $\begin{array}{c}\text { \% of production volume from the planned } \\
\text { annual increase of production volume }\end{array}$ & $\begin{array}{c}\text { \% of waste from the } \\
\text { total planned annual } \\
\text { production volume } \\
\text { Unused }\end{array}$ & Used \\
\cline { 2 - 7 } & BP & SP1 & SP2 & NP & 30 & 0 \\
\hline \multicolumn{7}{|c|}{ Investment in renewal } \\
\hline Variant 1 & 30 & 40 & 0 & 0 & 30 & 0 \\
\hline Variant 2 & 30 & 0 & 40 & 0 & 30 & 0 \\
\hline Variant 3 & 30 & 25 & 15 & 0 & 27 & 3 \\
\hline \multicolumn{7}{|l|}{ Investment in renewal and development } \\
\hline Variant 4 & 30 & 40 & 0 & 3 & 27 & 3 \\
\hline Variant 5 & 30 & 0 & 40 & 3 & 27 & 3 \\
\hline Variant 6 & 30 & 25 & 15 & 3 & 27 & 3 \\
\hline
\end{tabular}

\section{Evaluation of economic efficiency of investment variants}

The assessment of economic efficiency is carried out using dynamic financial criterion $N P V$. The $N P V$ monitors the profitability in euros for the entire life of the investment variant. The values of the financial criterion $N P V$, see Eq. (1), is determined by the amount of annual cash flow $(C F)$ converted to the present value at a discount rate $\left(d_{r}\right)$ considering the cost of capital and the amount of one-off investment costs $(I C)$. The formula for the calculation of the annual $C F$ from operating activities is expressed by Eq. (2).

$$
\begin{gathered}
N P V=\sum_{n=1}^{N} \frac{C F_{n}}{\left(1+d_{r}\right)^{n}}-I C \\
C F_{n}=E B I D T A_{n} \times\left(1-t_{n}\right)+D_{n} \times d_{r}
\end{gathered}
$$

EBITDA is the earning before interest, tax, depreciation and amortization; $D$ is yearly depreciation; $t$ is coefficient of income tax rate; $N$ is economic lifetime of the investment; $n$ is number of years of economic lifetime of the investment. 
EBITDA is affected by production and sales activities. The method of calculation for individual investment variants varies depending on the type/types of realized production. The method of calculation of the EBITDA indicator is expressed by Eqs. (3) to (5):

$$
\begin{gathered}
\operatorname{EBITDA}_{n}=\sum_{j=1}^{4} S_{n j}-\sum_{j=1}^{4} C_{n j} \\
S_{n j}=\left(p_{n j} \times P V_{n j}\right) \\
C_{n j}=C_{M A T}+C_{E}+S+C_{P}+C_{M a n d R}+C_{\text {other }}
\end{gathered}
$$

where $S$ is yearly sales; $C$ yearly costs; $p$ price for unit of production; $P V$ yearly production volume; $C_{M A T}$ yearly consumption of material; $C_{E}$ yearly consumption of energy, water, sewage etc., $S$ services; $C_{P}$ yearly personnel cost; $C_{\text {MandR }}$ yearly cost for maintenance and repair; $C_{O t h e r}$ yearly other expenses from operational activities; $j$ number of products (1-4).

The selected individual input variables, assessed as risk variables, are defined by probability

\begin{tabular}{|c|c|c|c|}
\hline Input risk variable & $\begin{array}{c}\text { Unit of } \\
\text { measure }\end{array}$ & Statistical characteristics & $\begin{array}{l}\text { Probability } \\
\text { distribution }\end{array}$ \\
\hline $\begin{array}{l}\text { Max yearly volume of processed } \\
\text { potatoes }\end{array}$ & $\mathrm{kg} /$ year & $\begin{array}{l}\text { Likeliest 40,000,000; } \\
\text { Min. 38,000,000; } \\
\text { Max. 44,000,000 }\end{array}$ & BetaPERT \\
\hline $\begin{array}{l}\% \text { of waste from the production } \\
\text { volume }\end{array}$ & $\%$ & $\begin{array}{c}\text { Likeliest 30; } \\
\text { Min. 25; Max. } 32\end{array}$ & BetaPERT \\
\hline $\begin{array}{l}\% \text { of mashed potato production from } \\
\text { waste of the whole production }\end{array}$ & $\%$ & $\begin{array}{c}\text { Likeliest 3; } \\
\text { Min. 2; Max. } 4\end{array}$ & BetaPERT \\
\hline Purchase price of electricity & $\mathrm{EUR} / \mathrm{kWh}$ & $\begin{array}{c}\text { Likeliest 0.16; } \\
\text { Min. 0.15: Max. 0.18 }\end{array}$ & Triangular \\
\hline Purchase price of oil & EUR/51 & $\begin{array}{c}\text { Likeliest 6.00; } \\
\text { Min. 5.70; Max. } 6.60\end{array}$ & Triangular \\
\hline Purchase price of water & $\mathrm{EUR} / \mathrm{m}^{3}$ & $\begin{array}{c}\text { Likeliest 3.01; } \\
\text { Min. 2.70; Max. } 3.35\end{array}$ & Triangular \\
\hline Purchase price of potatoes & $\mathrm{EUR} / \mathrm{kg}$ & $\begin{array}{c}\text { Likeliest 0.20; } \\
\text { Min. 0.18; Max. 0.25 }\end{array}$ & Triangular \\
\hline Average monthly personnel costs & $\begin{array}{l}\text { EUR/month/ } \\
1 \text { employee }\end{array}$ & $\begin{array}{c}\text { Likeliest 750; } \\
\text { Min. 680; Max. } 850\end{array}$ & BetaPERT \\
\hline Increase of other costs & EUR/year & $\begin{array}{c}\text { Likeliest 10,000; } \\
\text { Min. 9,000; Max. 11,000 }\end{array}$ & BetaPERT \\
\hline Water consumption & $\mathrm{m}^{3} /$ year & $\begin{array}{c}\text { Likeliest 2,000; } \\
\text { Min. 1,900; Max. 2,100 }\end{array}$ & BetaPERT \\
\hline Price of potato chips & EUR/kg & $\begin{array}{c}\text { Likeliest 0.70; } \\
\text { Min. 0.65; Max. } 0.80\end{array}$ & Triangular \\
\hline Price of cut potatoes & $\mathrm{EUR} / 5 \mathrm{~kg}$ & $\begin{array}{c}\text { Likeliest 2.50; } \\
\text { Min. 2.30; Max. } 2.80\end{array}$ & Triangular \\
\hline Price of peeled potatoes & $\mathrm{EUR} / 5 \mathrm{~kg}$ & $\begin{array}{c}\text { Likeliest 2.00; } \\
\text { Min. 1.80; Max. } 2.50\end{array}$ & Triangular \\
\hline Price of mashed potatoes & EUR/kg & $\begin{array}{c}\text { Likeliest 0.90; } \\
\text { Min. 0.85; Max. } 1.20\end{array}$ & Triangular \\
\hline
\end{tabular}
distributions (Table II).

Table II: Probability distributions and statistical characteristics of input variables.

4. Decision on the selection of an optimal investment variant

The selection of the most advantageous investment variant taking into account the risk is made through two approaches. 
The first approach is based on the analysis of the probability distribution of $N P V$. When comparing investment variants using the probability distribution of $N P V$, the option that has a higher mean value and lower variability is better. The variability is expressed by a coefficient of variance.

The second approach provides a comparative assessment of the investment variants using stochastic dominance rules, which are based on the cumulative probability distribution of $N P V$. The first rule of stochastic dominance prefers a higher value of the financial criterion over lower values. Graphical determination of the advantage of investment variants is based on the mutual position of the cumulative distribution functions of the compared investment variants. The cumulative distribution function of the preferred project lies to the right of the cumulative distribution function of the nonpreferred project, and their graphs do not intersect. In case the distribution functions intersect with each other, the second rule of stochastic dominance is followed. In this case, the size of the areas is compared. The preferred project has the cumulative distribution function to the right of the compared variant and at the same time, the area between the cumulative distribution functions is larger than the area, where the graph of the preferred project lies to the left. The final order of investment variants according to the above-mentioned rules is summarized using the method of comparison in pairs.

\section{Optimization of the most advantageous investment variant}

To find the optimal production program for the most advantageous investment variant, OptQuest is used. OptQuest is an optimization tool based on Scatter search methodology along with Tabu search strategies. The risk analysis of the optimal investment variant is supplemented by a sensitivity analysis, which informs about the influence of the uncertainty of input risk variables on the uncertainty of the output $(N P V)$.

\section{RESULTS}

\subsection{The selection of the optimal investment variant based on the probability distribution of $N P V$}

The evaluation of investment options considering risks is carried out using the Monte Carlo simulation method. Probabilistic distributions of individual investment variants take the form of a normal distribution. Their course is shown on the overlay chart (Fig. 3).

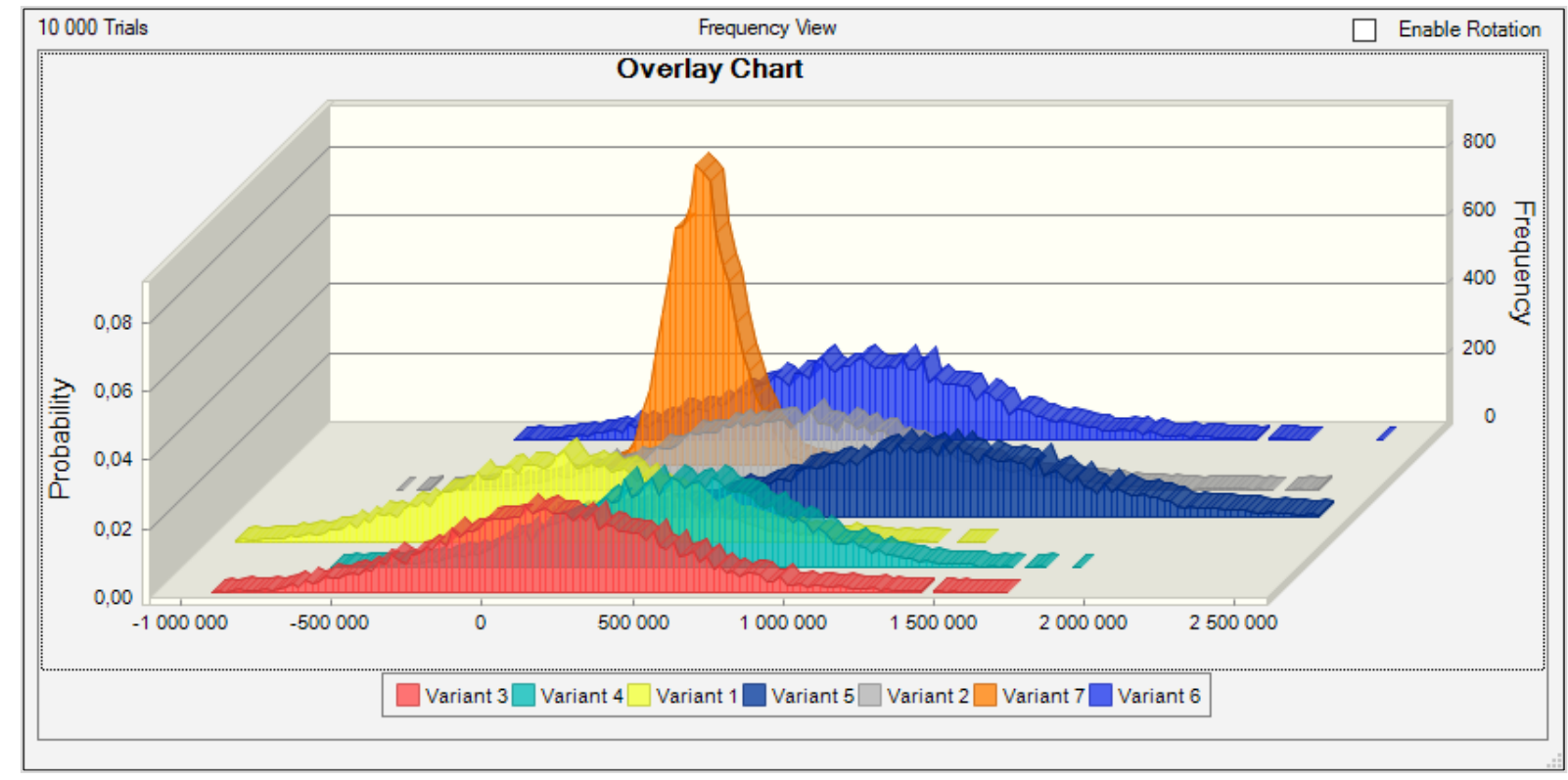

Figure 3: Probability distribution of $N P V s$ for all investment variants. 
Based on the data in Table III, it can be stated that the symmetry of the probability distributions of $N P V$ is approximately the same for all investment variants. Probability distributions of $N P V$, for all variants except variant 4 , are positive, i.e. right-hand skew, only variant 4 has a negative left-hand skew, which means that lower values prevail over higher ones. Given that the evaluated variants differ significantly in the amount of the mean values of $N P V$, as a decision criterion for determining the advantage of investment variants, the rule of mean value and coefficient of variation is used. Even in this case, the variant with a higher mean value and lower variability is better.

The application of the mean value and coefficient of variation rule confirms that investment variant 5 is dominant over investment variants $1,2,3,4,6$ and 7 because it has both characteristics considered better compared to them (Table III).

Table III: Statistical characteristics of $N P V s$ for all investment variants.

\begin{tabular}{|c|c|c|c|c|c|c|c|}
\hline Statistics & Variant 1 & Variant 2 & Variant 3 & Variant 4 & Variant 5 & Variant 6 & Variant 7 \\
\hline Base case & 47,630 & 600,583 & 165,907 & 521,435 & $1,074,388$ & 639,712 & 295,278 \\
\hline Mean & $\mathbf{6 1 , 6 7 6}$ & $\mathbf{7 1 1 , 5 2 6}$ & $\mathbf{2 1 3 , 9 3 5}$ & $\mathbf{5 4 7 , 9 7 4}$ & $\mathbf{1 , 2 3 5 , 9 0 5}$ & $\mathbf{7 3 8 , 4 8 3}$ & $\mathbf{2 8 1 , 3 7 5}$ \\
\hline $\begin{array}{c}\text { Coeff. of } \\
\text { variation }\end{array}$ & $\mathbf{6 . 2 3}$ & $\mathbf{0 . 6 2 6 2}$ & $\mathbf{1 . 8 4}$ & $\mathbf{0 . 6 5 7 3}$ & $\mathbf{0 . 3 6 9 1}$ & $\mathbf{0 . 5 4 9}$ & $\mathbf{0 . 3 8 0 8}$ \\
\hline Variance & $\begin{array}{c}147,806,1 \\
83,667\end{array}$ & $\begin{array}{c}198,551,9 \\
62,837\end{array}$ & $\begin{array}{c}154,662,1 \\
08,173\end{array}$ & $\begin{array}{c}129,721,4 \\
12,852\end{array}$ & $\begin{array}{c}208,075,8 \\
89,443\end{array}$ & $\begin{array}{c}164,341,4 \\
94,721\end{array}$ & $\begin{array}{c}11,482,44 \\
7,804\end{array}$ \\
\hline Skewness & 0.0373 & 0.301 & 0.1969 & -0.0088 & 0.2971 & 0.211 & 0.3072 \\
\hline Kurtosis & 3.1 & 3.2 & 3.22 & 3.01 & 3.21 & 3.14 & 2.97 \\
\hline $\begin{array}{c}\text { Standard } \\
\text { deviation }\end{array}$ & 384,456 & 445,592 & 393,271 & 360,169 & 456,153 & 405,391 & 107,156 \\
\hline
\end{tabular}

\subsection{The selection of the optimal investment variant based on the stochastic dominance}

The rules of stochastic dominance allow the examination of the entire probability distribution of the $N P V$ financial criterion. Preference of advantage of investment projects and restrictions on the application of the first and second rules of stochastic dominance are given in subchapter 2.2. A graphical representation of advantage of investment projects using their distribution functions is shown in Fig. 4. The determination of the order of advantage of investment variants according to the above stated rules is summarized using the method of comparison in pairs (Table IV). Also, in this case, the variant 5 is set as the dominant investment variant.

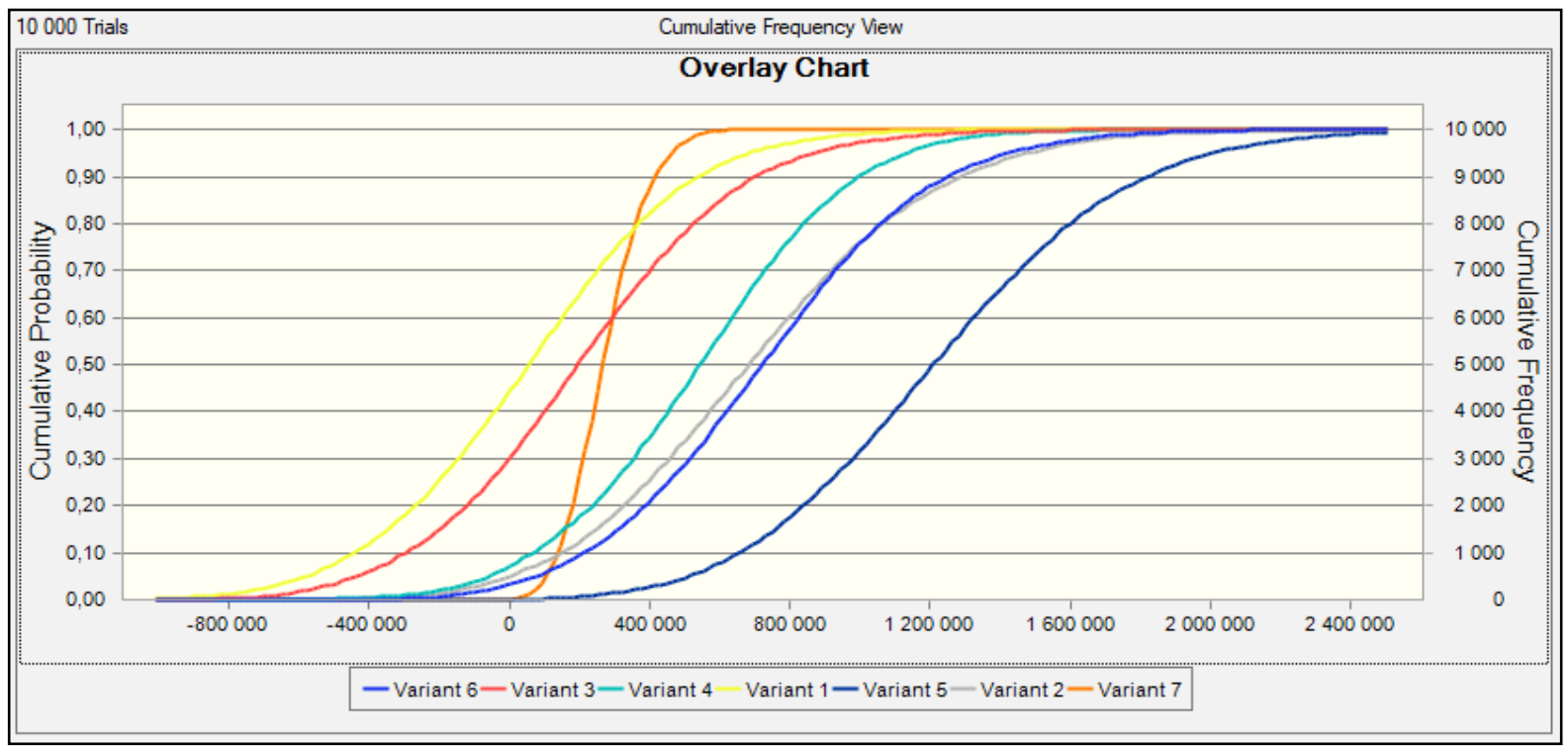

Figure 4: Cumulative distribution functions of $N P V s$ for all investment variants. 
By applying simulation procedures using the rule of mean value and coefficient of variation and the rules of stochastic dominance, it was confirmed that the most advantageous investment variant in both cases is variant 5 .

Table IV: The order of advantage of investment variants according to the rules of stochastic dominance.

\begin{tabular}{|c|c|c|c|c|c|c|c|}
\hline \multicolumn{6}{|c|}{ Investment variants } & \multirow{2}{*}{$\begin{array}{c}\text { Number of dominance } \\
0\end{array}$} & \multirow{2}{*}{$\begin{array}{c}\text { Order of investment variants } \\
7 .\end{array}$} \\
\hline $\begin{array}{c}\mathbf{1} \\
\text { (2) }\end{array}$ & $\begin{array}{c}1 \\
(3)\end{array}$ & $\begin{array}{c}\mathbf{1} \\
(4)\end{array}$ & $\begin{array}{c}\mathbf{1} \\
(5)\end{array}$ & $\begin{array}{c}\mathbf{1} \\
(6)\end{array}$ & $\begin{array}{c}1 \\
(7)\end{array}$ & & \\
\hline & $\begin{array}{c}\text { (2) } \\
3\end{array}$ & $\begin{array}{c}\text { (2) } \\
4\end{array}$ & $\begin{array}{c}2 \\
(5)\end{array}$ & $\begin{array}{c}2 \\
(6)\end{array}$ & $\begin{array}{c}\text { (2) } \\
7\end{array}$ & 4 & 3. \\
\hline & & $\begin{array}{c}3 \\
(4) \\
\end{array}$ & $\begin{array}{c}3 \\
(5)\end{array}$ & $\begin{array}{c}3 \\
(6) \\
\end{array}$ & $\begin{array}{c}3 \\
(7)\end{array}$ & 1 & 6. \\
\hline & & & $\begin{array}{c}4 \\
(5)\end{array}$ & $\begin{array}{c}4 \\
(6)\end{array}$ & $\begin{array}{c}(4) \\
7\end{array}$ & 3 & 4. \\
\hline & & & & $\begin{array}{c}\text { (5) } \\
6\end{array}$ & $\begin{array}{c}(5) \\
7\end{array}$ & 6 & 1. \\
\hline & & & & & $\begin{array}{c}(6) \\
7 \\
\end{array}$ & $\begin{array}{l}5 \\
2 \\
\end{array}$ & $\begin{array}{l}2 . \\
5 .\end{array}$ \\
\hline & & Tot & & dom & $\begin{array}{l}\text { ant } \\
\text { ond } 1 \\
\text { trule }\end{array}$ & $\begin{array}{l}\text { 21 } \\
\text { nvestment variant } \\
\text { le of stochastic dominance } \\
\text { of stochastic dominance ap }\end{array}$ & $\begin{array}{l}\text { pplied } \\
\text { ied }\end{array}$ \\
\hline
\end{tabular}

\subsection{OptQuest optimization of the production program for the optimal investment variant}

When the production program can be adapted to a certain extent to the pre-established conditions, it was for the investment variant 5 optimized. Optimization aims to increase investment profitability (i.e. $N P V$ ) by a slight change in the percentage share of individual products. The decision variables BP, SP1, SP2, NP are set in the intervals according to Fig. 5. The optimization requirement, besides $N P V$ maximization, is also the coefficient of variation $(\leq 0.30)$. The results of the optimization are shown in Fig. 6.

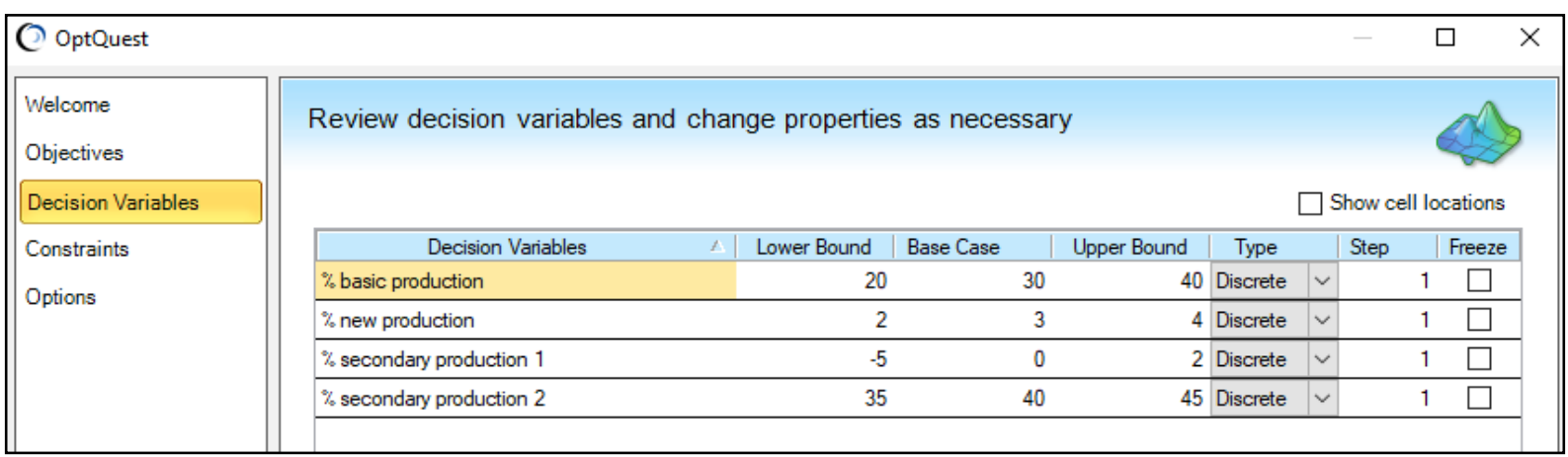

Figure 5: Decision variables and their parameters.

By optimizing production at $23 \% \mathrm{BP}, 2 \% \mathrm{SP} 1,45 \% \mathrm{SP} 2$ and $4 \% \mathrm{NP}$, the maximum mean value of $N P V$ variant 5 (opt) will be reached in the amount of EUR 1,692,316, which means an increase in profitability compared to $N P V$ variant 5 by EUR 617,928 and a reduction of risk of investment variant expressed by a coefficient of variation of 0.27 . The risk analysis of investment variant 5 is supplemented by a sensitivity analysis, which provides information on the impact of the uncertainty of individual risk input variables on the uncertainty of the output. The sensitivity chart (Fig. 7) shows the percentage contribution of all risk factors that contributed more than $1 \%$ to the total uncertainty of the value of the monitored financial criterion. 


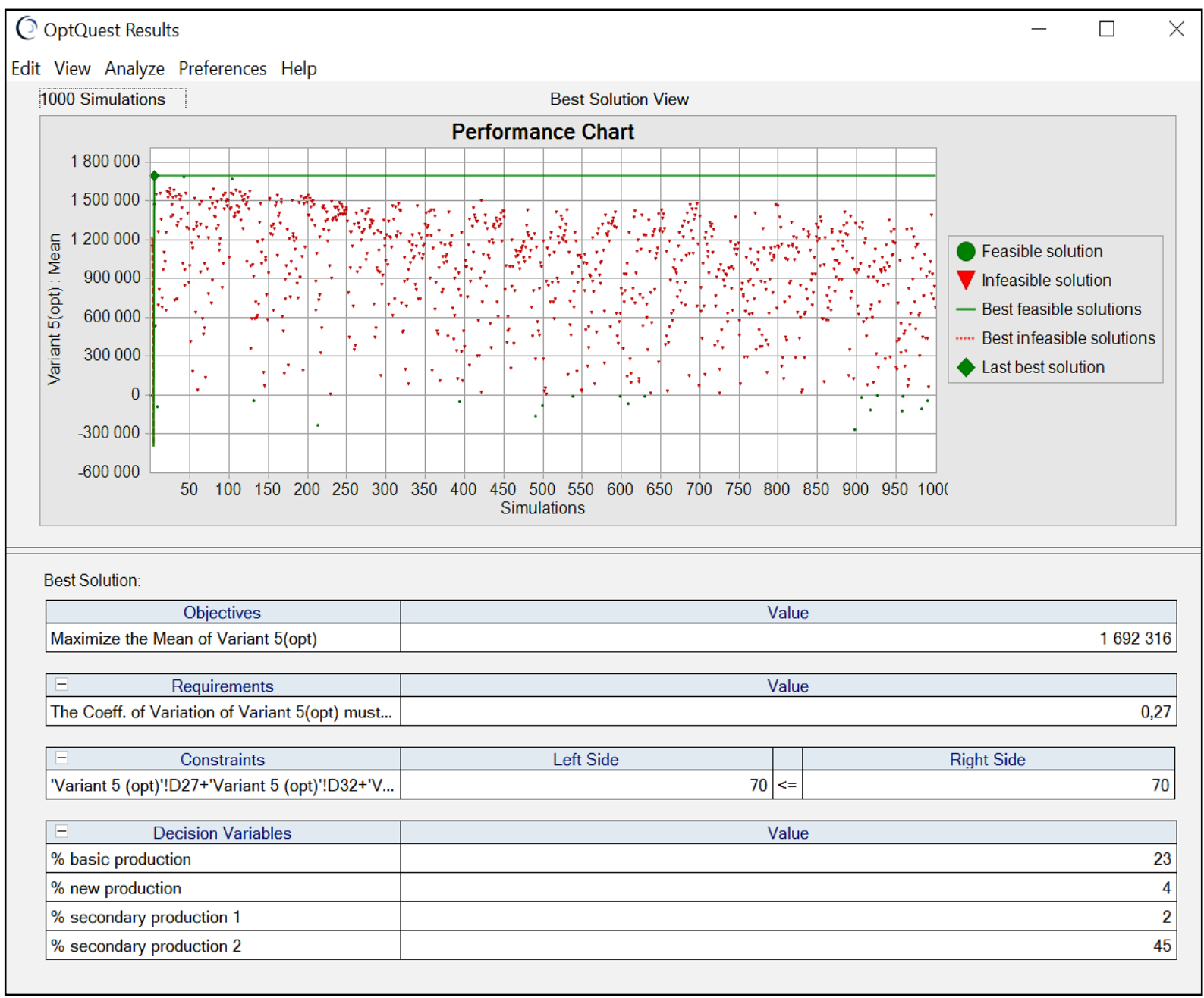

Figure 6: OptQuest optimization output.

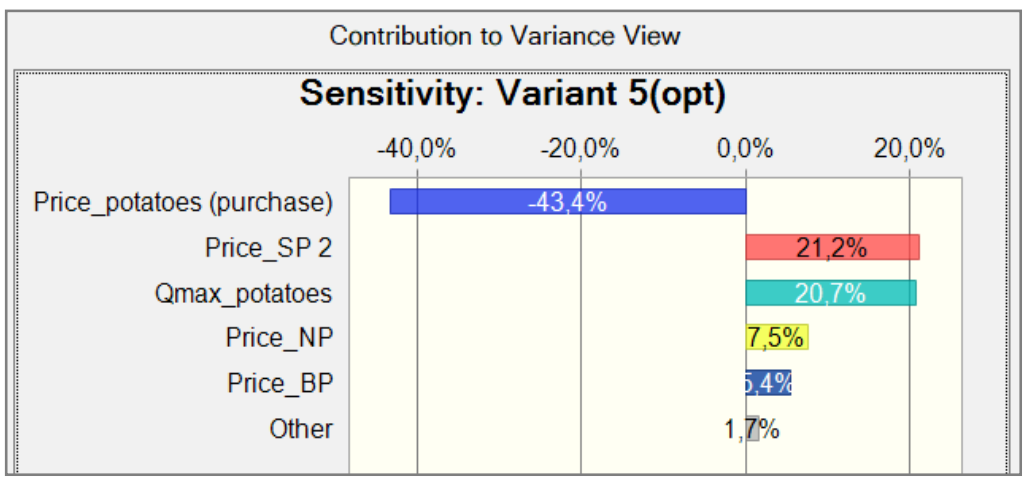

Figure 7: Sensitivity chart of input risk variables to $N P V$ for variant 5 (opt).

The uncertainty of the forecast of the $N P V$ financial criterion is mostly influenced by the following three input variables: uncertainty of the purchase price up to $43.4 \%$, the price of SP1 contributes $21.2 \%$ and annual volume of material processing is reflected in the output uncertainty to the extent of $20.7 \%$.

The identification of the most serious risk factors is important from the point of view of risk management. High output variability reduces a forecast reliability. The identification of these risk factors makes it possible to choose measures to increase the probability of achieving the expected result or to reduce the adverse effects of their changes. 


\section{CONCLUSION}

Investment activity is always associated with risk, and therefore methods supporting the integration of risk into investment decision-making increase the quality of investment decisionmaking process. The case study introduced two approaches based on Monte Carlo simulation to select the most advantageous investment variant from seven possible ones. Investment variants were assessed from the view of economic efficiency and risk. The first approach was based on the analysis of the distribution function of $N P V$ and applied the mean value and coefficient of variation as the decision criterion. The second approach, based on the cumulative probability distribution of $N P V$, provides a comparative assessment of the investment variants using stochastic dominance rules. The first and the second rule of stochastic dominance was applied. The prioritization of investment variants was carried out by pairwise comparison. Both approaches led to the choice of the same investment variant. In order to increase the profitability of the selected investment variant and reduce its risk, OptQuest optimization was subsequently implemented. Optimization aimed to maximize $N P V$ and simultaneously not exceed the required value of the coefficient of variation. The result of optimisation was the production plan, changed according to these requirements. Subsequent sensitivity analysis pointed out the risk factors that contributed the most to the total uncertainty of $N P V$.

The presented approaches using Monte Carlo simulations allow considering the influence of risk input variables on the output simultaneously. That means the direct incorporation of input variables uncertainty into the output. Results of simulations provide a picture of forecast reliability by statistical characteristics and allow examination of risks' impact on the result. That is the quantitative expression of the forecast reliability and the severity of the risk factors. In this way, the risk is included explicitly in investment decision-making, and the result is a set of data directly applicable in risk management. The simulation model can be easily re-used for changed requirements and optimized by including further restrictions, if necessary. That is a significant benefit of the presented approaches to decision-making and risk management.

However, some limitations concerning the application of the Monte Carlo simulations in decision-making need to be mentioned. In practice, widely used deterministic calculation of dynamic financial criteria does not provide versatile integration of risk into investment decision-making. In terms of the subjective influence of the assessor, it is more independent. In the stochastic-simulation approach, the result is strongly dependent on the assessor's expertise, despite the possibility of using software simulation. The assessor can provide misleading inputs to the decision-making process by incorrect estimation of uncertainty, the definition of distributions, and selection of risk factors. Unprofessional evaluation of simulation outputs leads to wrong investment decisions and undesirable economic impacts.

\section{ACKNOWLEDGEMENT}

This research was funded by grant KEGA 009TUKE-4/2020, KEGA 012TUKE-4/2019, VEGA 1/0638/19 and APVV SK-SRB-18-0053.

\section{REFERENCES}

[1] Mańkowski, C.; Weiland, D.; Abramović, B. (2019). Impact of railway investment on regional development - case study of pomeranian metropolitan railway, Promet-Traffic \& Transportation, Vol. 31, No. 6, 669-679, doi:10.7307/ptt.v31i6.3231

[2] Garnov, A. P.; Zvyagin, L.; Sviridova, O. (2019). Analysis of investment risks as a complex system using fuzzy logic and uncertainty management methods, International Journal of Economics and Business Administration, Vol. 7, No. 1, 447-458, doi:10.35808/ijeba/290 
[3] Jovčić, S.; Pruša, P.; Dobrodolac, M.; Švadlenka, L. (2019). A proposal for a decision-making tool in third-party logistics (3PL) provider selection based on multi-criteria analysis and the fuzzy approach, Sustainability, Vol. 11, No. 15, Paper 4236, 23 pages, doi:10.3390/su11154236

[4] Liu, X.; Wang, Z.; Zhang, S.; Chen, Y. (2020). Investment decision making along the B\&R using critic approach in probabilistic hesitant fuzzy environment, Journal of Business Economics and Management, Vol. 21, No. 6, 1683-1706, doi:10.3846/jbem.2020.13182

[5] Karasan, A. (2019). A novel hesitant intuitionistic fuzzy linguistic AHP method and its application to prioritization of investment alternatives, International Journal of the Analytic Hierarchy Process, Vol. 11, No. 1, 127-142, doi:10.13033/ijahp.v11i1.610

[6] Hashemizadeh, A.; Ju, Y.; Bamakan, S. M. H.; Le, H. P. (2021). Renewable energy investment risk assessment in belt and road initiative countries under uncertainty conditions, Energy, Vol. 214, Paper 118923, 18 pages, doi:10.1016/j.energy.2020.118923

[7] Xu, X. (2020). Risk factor analysis combined with deep learning in the risk assessment of overseas investment of enterprises, Plos One, Vol. 15, No. 10, Paper e0239635, 14 pages, doi:10.1371/ journal.pone. 0239635

[8] Zhang, J. (2020). Investment risk model based on intelligent fuzzy neural network and VaR, Journal of Computational and Applied Mathematics, Vol. 371, Paper 112707, 10 pages, doi:10.1016/j.cam.2019.112707

[9] Nowak, M. (2005). Investment projects evaluation by simulation and multiple criteria decision aiding procedure, Journal of Civil Engineering and Management, Vol. 11, No. 3, 193-202, doi: $10.1080 / 13923730.2005 .9636350$

[10] Zurek, J.; Ziółkowski, J.; Szkutnik-Rogoz, J. (2019). Stochastic dominance application for optimal transport company selection, AIP Conference Proceedings, Vol. 2078, Paper 020074, 8 pages, doi:10.1063/1.5092077

[11] Repiský, J. (2018). Application of modelling techniques in formation and assessment of investment projects in orchard, Albanian Journal of Agricultural Sciences, Special Edition - Proceedings of ICOALS 2018, 731-738

[12] Kauffman, R. J.; Liu, J.; Ma, D. (2015). Technology investment decision-making under uncertainty, Information Technology and Management, Vol. 16, No. 2, 153-172, doi:10.1007/ s10799-014-0212-2

[13] Vrecko, I.; Kovac, J.; Rupnik, B.; Gajsek, B. (2019). Using queuing simulation model in production process innovations, International Journal of Simulation Modelling, Vol. 18, No. 1, 47-58, doi:10.2507/IJSIMM18(1)458

[14] Fedorko, G.; Molnar, V.; Honus, S.; Neradilova, H.; Kampf, R. (2018). The application of simulation model of a milk run to identify the occurrence of failures, International Journal of Simulation Modelling, Vol. 17, No. 3, 444-457, doi:10.2507/IJSIMM17(3)440

[15] Török, Á.; Szalay, Z.; Uti, G.; Verebélyi, B. (2020). Modelling the effects of certain cyber-attack methods on urban autonomous transport systems, case study of Budapest, Journal of Ambient Intelligence and Humanized Computing, Vol. 11, No. 4, 1629-1643, doi:10.1007/s12652-01901264-8

[16] Mikušová, N.; Tomková, E.; Dovica, M.; Debelic, B.; Peric-Hadzic, A.; Zajac, J. (2018). Use of simulation for waste management and reverse material flow, Advances in Science and Technology Research Journal, Vol. 12, No. 4, 136-143, doi:10.12913/22998624/94965

[17] Kumar, L.; Jindal, A.; Velaga, N. R. (2018). Financial risk assessment and modelling of PPP based Indian highway infrastructure projects, Transport Policy, Vol. 62, 2-11, doi:10.1016/ j.tranpol.2017.03.010

[18] Albana, A. S.; Saputra, Y. A. (2019). Financial risk assessment for power plant investment under uncertainty using Monte Carlo simulation, Proceedings of the 2019 International Conference on Technologies and Policies in Electric Power \& Energy, 6 pages, doi:10.1109/ IEEECONF48524.2019.9102631

[19] Yuan, T.; Xiang, P.; Li, H.; Zhang, L. (2020). Identification of the main risks for international rail construction projects based on the effects of cost-estimating risks, Journal of Cleaner Production, Vol. 274, Paper 122904, 9 pages, doi:10.1016/j.jclepro.2020.122904

[20] Marchenko, R. S.; Cherepovitsyn, A. E. (2017). Improvement of the quality of calculations using the Monte Carlo simulation method in the evaluation of mining investment projects, Proceedings 
of the 2017 International Conference Quality Management, Transport and Information Security, Information Technologies, 247-251, doi:10.1109/ITMQIS.2017.8085805

[21] Dheskali, E.; Koutinas, A. A.; Kookos, I. K. (2020). Risk assessment modeling of bio-based chemicals economics based on Monte-Carlo simulations, Chemical Engineering Research and Design, Vol. 163, 273-280, doi:10.1016/j.cherd.2020.09.011

[22] Pringles, R.; Olsina, F.; Penizzotto, F. (2020). Valuation of defer and relocation options in photovoltaic generation investments by a stochastic simulation-based method, Renewable Energy, Vol. 151, 846-864, doi:10.1016/j.renene.2019.11.082

[23] Masdías-Bonome, A. E.; Orosa, J. A.; Vergara, D. (2020). A new methodology for decisionmaking in buildings energy optimization, Applied Sciences, Vol. 10, No. 13, Paper 4558, 21 pages, doi:10.3390/app10134558

[24] Hacığlu Hoke, S.; Kapetanios, G. (2020). Common correlated effect cross-sectional dependence corrections for nonlinear conditional mean panel models, Journal of Applied Econometrics, Vol. 36, 125-150, doi:10.1002/jae.2799

[25] Meins, E.; Sager, D. (2015). Sustainability and risk: combining Monte Carlo simulation and DCF for Swiss residential buildings, Journal of European Real Estate Research, Vol. 8, No. 1, 66-84, doi:10.1108/JERER-05-2014-0019

[26] Samokhvalov, Y. (2021). Risk assessment of innovative projects based on fuzzy modeling, Babichev, S.; Lytvynenko, V.; Wójcik, W.; Vyshemyrskaya, S. (Eds.), Lecture Notes in Computational Intelligence and Decision Making, ISDMCI 2020, Advances in Intelligent Systems and Computing, Springer, Cham, 265-281, doi:10.1007/978-3-030-54215-3_17

[27] Kannan, D.; Moazzeni, S.; Darmian, S. M.; Afrasiabi, A. (2021). A hybrid approach based on MCDM methods and Monte Carlo simulation for sustainable evaluation of potential solar sites in east of Iran, Journal of Cleaner Production, Vol. 279, Paper 122368, 19 pages, doi:10.1016/ j.jclepro.2020.122368

[28] Juan, A. A.; Faulin, J.; Grasman, S. E.; Rabe, M.; Figueira, G. (2015). A review of simheuristics: extending metaheuristics to deal with stochastic combinatorial optimization problems, Operations Research Perspectives, Vol. 2, 62-72, doi:10.1016/j.orp.2015.03.001 